RESEARCH ARTICLE

\title{
Hybrid AC and DC power distribution
}

\author{
S. Jayawardena ${ }^{1}$, P. Binduhewa ${ }^{2}$ and J.B. Ekanayake ${ }^{2, *}$

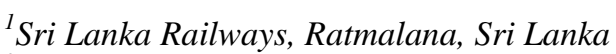 \\ ${ }^{2}$ Department of Electrical and Electronic Engineering, University of Peradeniya, Peradeniya, Sri Lanka
}

Received:26/02/2017; Accepted:15/05/2017

\begin{abstract}
Interest in the use of DC for medium and low voltage distribution circuits is growing as a means of reducing the multiple power conversion stages associated with connecting renewable energy sources and DC powered consumer electronic devices to the existing AC system.

The possibility of carrying AC power and injected DC power at the distribution transformer in the same distribution line and filtering out them separately to $\mathrm{AC}$ and DC loads were investigated. Both simulations and laboratory experiments were used to prove this concept of hybrid distribution. A comparative study was carried out to show that the proposed hybrid solution minimises the energy losses in power conversion stages when integrating renewables.
\end{abstract}

Keywords: DC distribution, power converters, energy efficiency.

\section{INTRODUCTION}

The first ever electrical distribution is using DC by Thomas Alva Edison in 1882 in Pearl Street, New York. However, due to inability of boosting DC voltage at different stages, the world electrical distribution shifted to AC. This was triggered by the invention of the transformer by Nikola Tesla in 1897. Since then the electrical distribution was carried out mainly by AC.

The interest for the use of DC for power transmission at high voltage levels has gained momentum since 1954. Power transfer by High Voltage Direct Current (HVDC) is used to connect asynchronous AC systems and for circuits of underground or submarine high voltage cables longer than about $50 \mathrm{~km}$ (depending on the voltage) (Andersen, B.R. et.al., 2000, Kirby N. M. et.al., 2002). HVDC is also considered for the connection of large wind farms far offshore (Kirby, N. M. et.al., 2002, Asplund, G. et.al., 1998). Further, HVDC becomes an attractive alternative to $\mathrm{AC}$ transmission when length of the overhead line exceeds about $600 \mathrm{~km}$.

Even though DC high voltage transmission is now well established, the use of DC at Medium Voltage (MV), i.e. $1 \sim 30 \mathrm{kV}$ and Low Voltage (LV), i.e. $\langle\sim 1 \mathrm{kV}$, levels is very limited. However, interest in the use of DC for MV and LV distribution circuits is growing for the following reasons:

- Photovoltaic (PV) panels produce a DC output voltage and before being connected to an $\mathrm{AC}$ grid the DC output must be converted to AC. Further, modern wind turbines employ two converters (AC to DC and DC to $\mathrm{AC}$ ) with a DC bus in between. When connecting renewable energy sources to the existing AC system through multiple power conversion stages, there will be increasing complexity and reduced efficiency. Instead, if the renewable energy sources are directly connected to DC networks the power loss in converters can be eliminated thus saving $2.5 \%$ to $10 \%$ of the energy transferred (Zhang, W.et.al., 2012).

- Many distributed generation systems, Microgrids and energy storage devices use power electronic interfaces to the AC grid. These sources are compatible with DC distribution systems where the energy can be used directly to supply loads and/or energy storage devices. This results in reduced conversion losses (Hammerstrome, D. J., 2007).

- To provide reliability against unplanned AC outrages, uninterruptible power supplies (UPS), which are essentially battery storage systems with a DC bus, are employed. Furthermore, Electric Vehicles (EVs) are not only significant consumers of electrical 
power, but their batteries could also provide improved grid reliability and energy storage whenever they are grid-connected. The conversion stages associated with these distributed energy storage devices are reduced if they are used with a DC network.

- With the unprecedented development of electronic technology, DC powered consumer electronic devices such as computers, televisions and cordless tools have become a significant part of the system load. For example in a typical home, except the washing machine and fridge/freezer all the other appliances/components are DCinternal or native-DC loads. Most of these appliances when connected to the AC system employ Switch Mode Power Supplies (SMPSs).Efficiency of these SMPSsare rather low and is in the range of $30-40 \%$ for external converters like those used in laptop computers and $65-70 \%$ of internal converters. If these appliances are fed with DC, a DC to DC converter is required in some application to match the DC bus voltage with the internal voltage of the appliance. The efficiency of a DC to DC converter is rather high and is in the range of 85-95\%. As the energy consumption of consumer electronic equipment increases, supplying energy through the traditional AC system will become less efficient and more complex, because more of the energy must be converted to DC.

- Overall energy efficiency can be enhanced when in addition to a low-voltage AC network, buildings and homes also have a low-voltage DC supply. In the future, homes will have heat-pumps, photovoltaic systems and charging points for Electric Vehicles. All these devices use power electronic converters with filters to connect to the $\mathrm{AC}$ grid. Major cost savings can be realized by avoiding the complex converter systems.

Different concepts for distribution of electricity through DC at MV and LV levels and their comparison with AC system is reported in the literature.Salonen, P. et.al. (2008) discusses a number of different connection topologies of LVDC distribution system and the way loads can be connected to them. In order to utilise all three wires of the existing LV distribution system a $\pm 750 \mathrm{~V}$ bipolar DC distribution is considered and protection required for safety is discussed. A loss comparison between AC vs DC distribution is reported in (Starke, M. et.al., 2008). Even though the exact benefits of DC distribution depends on the system voltage used and the proportion of AC to DC loads, thisarticle shows that for similar maximum voltage levels ( $\sqrt{2}$ times $\mathrm{rms}$ for $\mathrm{AC}$ ) and AC loads to DC loads proportion of $50 \%$ to $50 \%$, the DC incur low losses compared to AC. A comparison of DC distribution over AC for MV applications are presented in (Korytowski, M., 2011). A comparison of the performance of the MVDC system over MVAC system is presented under steady state operation and under different faults. Even though DC distribution is considered as a preferred option considering the benefits such as higher power capacity for a given cable size, enhanced reliability, low losses and voltage quality improvement (Salonen, P. et.al., 2008), the most of the configurations proposed in the literature demand considerable changes to the existing infrastructure and more complex arrangements.

Considering the fact that existing loads such as motors are AC driven and many other loads such as entertainment and IT equipment are DC driven, in this paper a hybrid distribution approach is proposed. Even though a hybrid approach is presented in (Pasonen, R., 2014), it requires five wires for distribution of $\mathrm{AC}$ and $\mathrm{DC}$ separately. Only the neutral wire is utilised by both systems. In Basu, K.P. et.al.(2005) and Gopi, C.et.al. (2016), the feasibility of converting a double circuit $\mathrm{AC}$ line into composite AC-DC power transmission is demonstrated. Here, DC power is obtained through a 12-pulse Rectifier Bridge used in HVDC and injected to the neutral point of the secondary of sending end transformer and inverted at the receiving end. Three conductors of the second line provide return path for the DC current. Zigzag connected winding is used at both ends to avoid saturation of transformer due to DC. The simultaneous AC-DC transmission has been investigated in Choudhary,V.et.al. (2011)using PSCAD/EMTDC simulations to study its feasibility for a double circuit line.The schemes presented in (Basu, K.P.et.al., 2005,Choudhary,V.et.al., 2011) are mainly for transmission applications, and needs two three winding transformers of Star-Zigzag-Delta and four converter bridged on both sending and receiving ends. This arrangement will not be technically or economically attractive for the 
distribution end of the power system. Therefore in this paper a scheme which can be introduced to distribution circuits with minimum changes to the existing scheme is proposed.

\section{AC AND HYBRID DISTRIBUTION OF PV \\ PV} power distribution using AC: Existing scheme

In existing applications, a PV array is connected to the AC system through an inverter. Commonly used topologies are: strings connected in parallel to a central inverter, strings connected through multiple inverters, and individual modules connected through micro-inverters. The connection of a PV array into a central inverter is shown in Figure 1. In the figure central inverter operating on PWM is utilised. The voltage is then boost to $33 \mathrm{kV}$ and connected to the $33 \mathrm{kV}$ distribution busbar.

\section{Hybrid PV power distribution - Proposed scheme}

Figure 2 shows a hybrid scheme in which output DC from the PV array is send through the distribution line as a train of pulses. This scheme needs a three winding transformer at the consumer end.

The different components in Figure 2 are described below:

\section{a) Injection transformer}

This is a three-phase distribution transformer of which the primary is delta-connected. As shown in Figure 3, the secondary is connected as star. The pulse output of the single phase H-bridge is connected between the star point and the ground. The phase voltages are given by:

$$
\begin{aligned}
& v_{a}=v_{\text {pulse }}(t)+V_{m} \sin \omega t \\
& v_{b}=v_{\text {pulse }}(t)+V_{m} \sin (\omega t-2 \pi / 3) \\
& v_{c}=v_{\text {pulse }}(t)+V_{m} \sin (\omega t-4 \pi / 3)
\end{aligned}
$$

where $v_{\text {pulse }}(t)$ is the pulse waveform injected to the neutral and $V_{m}$ is the maximum value of AC voltage.

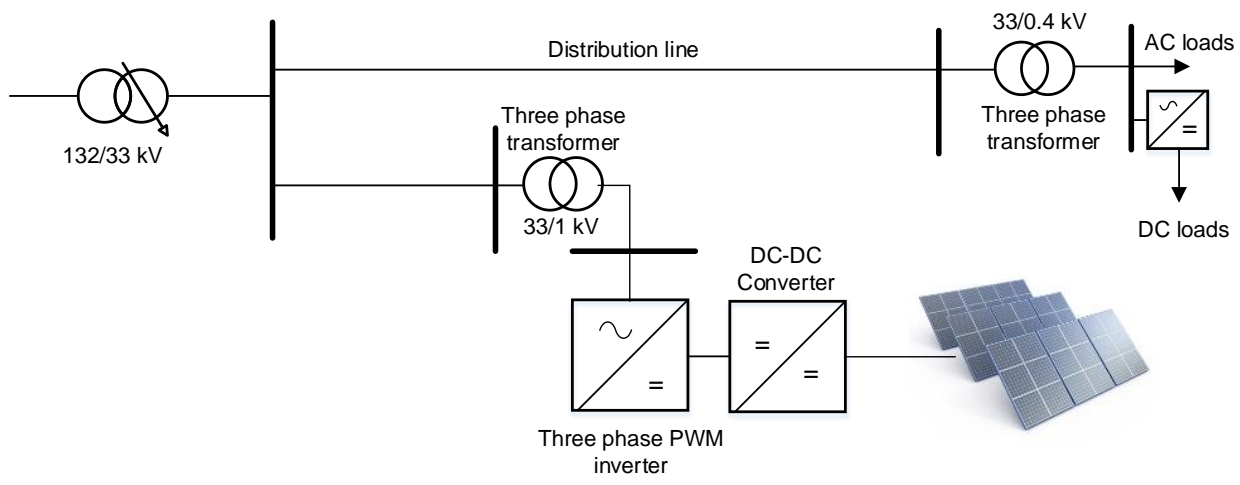

Figure 1: Connection of a large PV array to the distribution network through an AC connection.

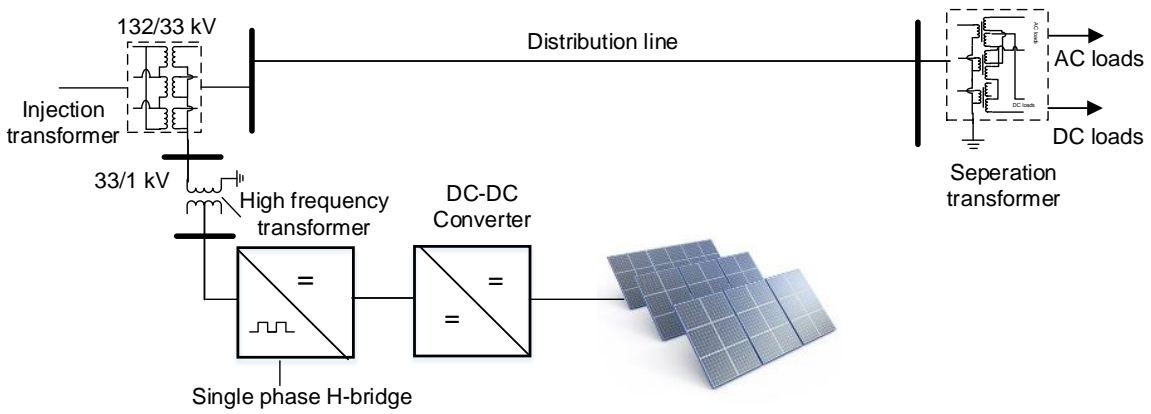

Figure 2: Proposed connection of a large PV array to the distribution network. 


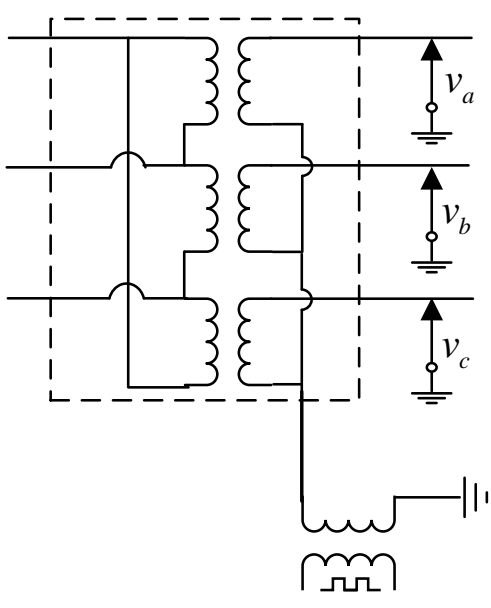

Figure 3: Injection transformer.

b) Separation transformer

This is a three-phase, three-winding transformer of which the primary is star-grounded. Secondary windings are connected in such a way that the difference between two output phase voltages makes the AC voltage of one phase (shown in Figure 4) and similarly the other two phases. The injected pulse voltage is obtained by connecting all the tertiary windings in series. In order to minimise losses associated with the high frequency pulse passes through this transformer, core should be designed with low-loss magnetic material.

Therefore, the waveform of the extracted AC voltage of one phase in the secondary side of the separation transformer is given by:

$$
\begin{aligned}
v_{a b}= & k^{\prime}\left[v_{\text {pulse }}(t)+V_{m} \sin \omega t\right] \\
& -k^{\prime}\left[v_{\text {pulse }}(t)+V_{m} \sin (\omega t-2 \pi / 3)\right] \\
= & \sqrt{3 k^{\prime} V_{m} \sin (\omega t-2 \pi / 6)}
\end{aligned}
$$

where $k^{\prime}$ is the turns ratio between primary and secondary

Similarly the three-phase system is formed by $v_{\mathrm{bc}}$ and $v_{\mathrm{ca}}$ (only $v_{\mathrm{ab}}$ is shown in Figure 4)

The waveform of output pulse voltage from the series connected tertiaries of the separation transformer is given by:

$$
\begin{aligned}
v_{a b}= & k "\left[v_{\text {pulse }}(t)+V_{m} \sin \omega t\right] \\
& +k^{\prime}\left[v_{\text {pulse }}(t)+V_{m} \sin (\omega t-2 \pi / 3)\right] \\
& +k^{\prime}\left[v_{\text {pulse }}(t)+V_{m} \sin (\omega t-4 \pi / 3)\right. \\
= & 3 k^{\prime \prime} v_{\text {pulse }}(t)
\end{aligned}
$$

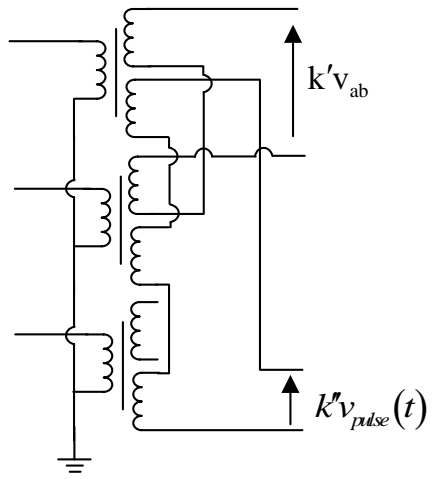

Figure 4: Separation transformer.

\section{c) Single phase H-bridge}

Figure 5 shows the H-bridge circuit. When two Insulated Gate Bipolar Transistors (IGBT), $\mathrm{S}_{1}$ and $S_{4}$ are ON and two IGBTs, $S_{3}$ and $S_{2}$ are OFF. The voltages across $\mathrm{A}$ and $\mathrm{B}\left(\mathrm{V}_{\mathrm{AB}}\right)$ hasa positive voltage corresponding to the output of the PV array. Once the states of switches are inverted, the terminal voltage becomes the negative of the PV output voltage. In this application the ON/OFF time of each pair of switches was set to be $50 \%$ of the switching period thus to obtain 0.5 duty cycle pulse waveform.

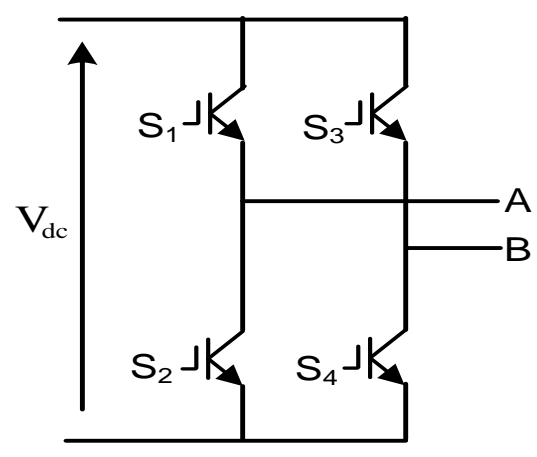

Figure 5: H-bridge. 


\section{Comparison of the $\mathrm{AC}$ and Hybrid distribution}

In this comparison it was assumed that the PV panels associated with two systems shown in Figures 1 and 2 are identical. The following assumptions were made:

Rated voltage of the PV panel

$$
\begin{aligned}
& V_{P V} \\
& P_{P V}
\end{aligned}
$$

Rated power of the PV panel

Grid side phase voltage (secondary of the transformer)

Modulation index of PWM $V_{\text {Grid }}$

PWM and pulse converter is operating at the unity power factor

Three phase PWM converter is shown in Figure 6.

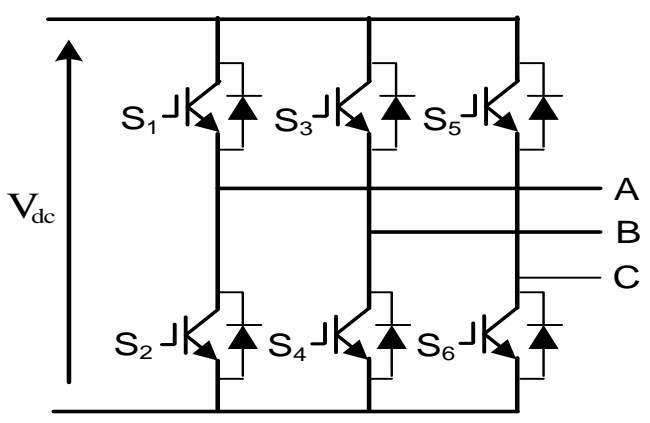

Figure 6: Three phase converter.

The relationship between grid side voltage and $V_{d c}$ is given by
$V_{\text {Grid }}=0.353 m_{a}$

Assuming at the rated conditions, the duty ratio of the DC-DC converter is $d_{1}$

$V_{d c}=d_{1} V_{P V}$

Figure 7 shows the voltage and current waveforms for PWM switching. It was assumed that the mid-point of the dc link is connected to the neutral of the input transformer. Therefore the voltage rating of the IGBTs is given by

Voltage rating $=V_{d c}=d_{1} V_{P V}=\frac{V_{G r i d}}{0.353 m_{a}}$

Assuming that the efficiency of the DC-DC converter is $\eta_{D C}$ and that of the converter is $\eta_{V S C}$

$3 V_{\text {Grid }} I_{\text {Grid }}=P_{P V} \times \eta_{D C} \eta_{\text {Pulse }}$

where $I_{\text {Grid }}$ is the rms value of the ac current shown in Figure 2

Therefore the current rating of the switch is given by

Current rating $=0.33 \frac{P_{P V} \times \eta_{D C} \eta_{\text {Pulse }}}{V_{\text {Grid }}}$

Assuming that the IGBT and its anti-parallel diode has the same ON state voltage drop, $V_{O N}$, the conduction losses were calculated approximately as:

Conduction losses $=3 \times I_{\text {Grid }} \times V_{O N}$

If the PWM frequency is $\mathrm{f}_{\mathrm{PWM}}$, switching losses are approximately given by $3 V_{d c} I_{G r i d} f_{P W M}$.

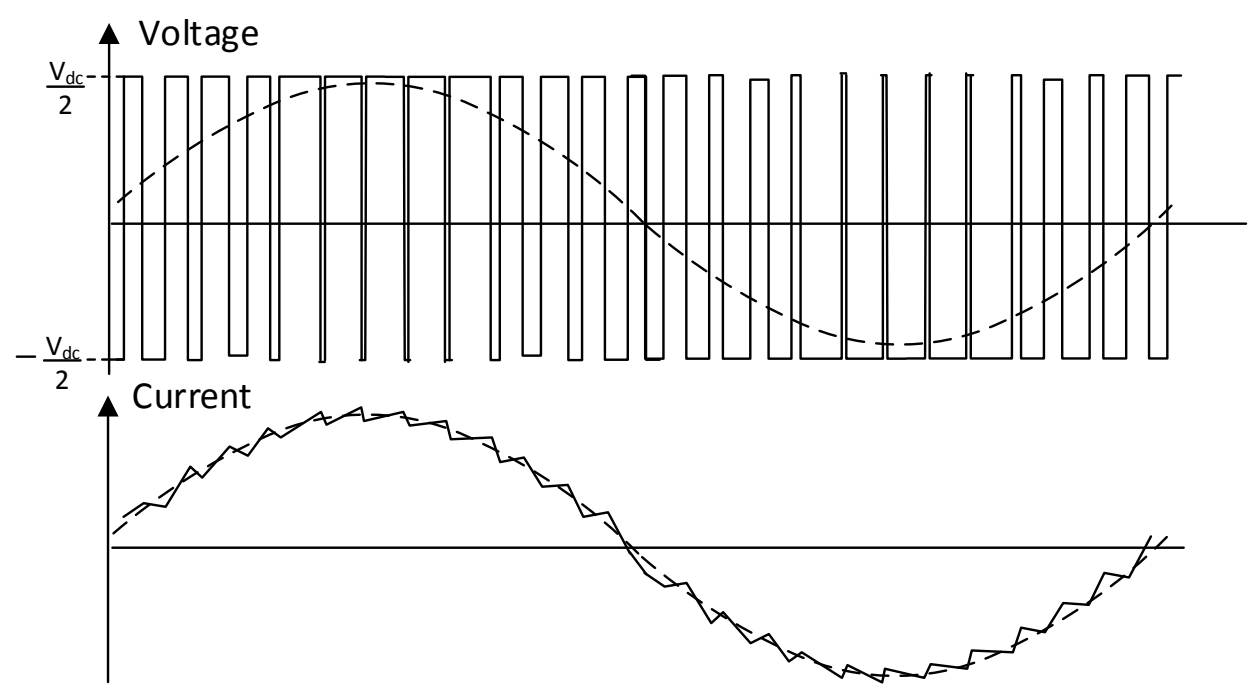

Figure 7: Current and voltage for PWM switching. 
For the H-bridge converter shown in Figure 5, where $\mathrm{I}_{\text {Grid }}$ is the rms value of the ac current the relationship between grid side voltage and $V_{d c}$ is given by

$V_{\text {Grid }}=V_{d c}$ shown in Figure 4

Therefore the current rating of the switch is given by

Current rating $=\frac{P_{P V} \times \eta_{D C} \eta_{P u l s e}}{V_{\text {Grid }}}$

of the DC-DC converter is $\mathrm{d}_{2}$

$V_{d c}=d_{2} V_{P V}$

Figure 8 shows the voltage and current waveforms for pulse switching. Therefore the voltage rating of the IGBTs is given by

Voltage rating $=V_{d c}=d_{2} V_{P V}=V_{\text {Grid }}$

Assuming that the efficiency of the DC-DC converter is $\eta_{D C}$ and that of the converter is $\eta_{\text {pulse }}$

$V_{\text {Grid }} I_{\text {Grid }}=\eta_{P V} \times \eta_{D C} \eta_{\text {Pulse }}$

Assuming that the ON state voltage drop of IGBT is $V_{O N}$, the conduction losses were calculated approximately as:

Conduction losses $=2 I_{\text {Grid }} \times V_{O N}$

If the switching frequency is $f_{\text {pulse }}$, switching losses are approximately given by $V_{d c} I_{\text {Grid }} f_{\text {pulse }}$.

Table 1 summarises the components and their ratings required for the current scheme and the proposed scheme to interface the PV array to $33 \mathrm{kV}$ network.
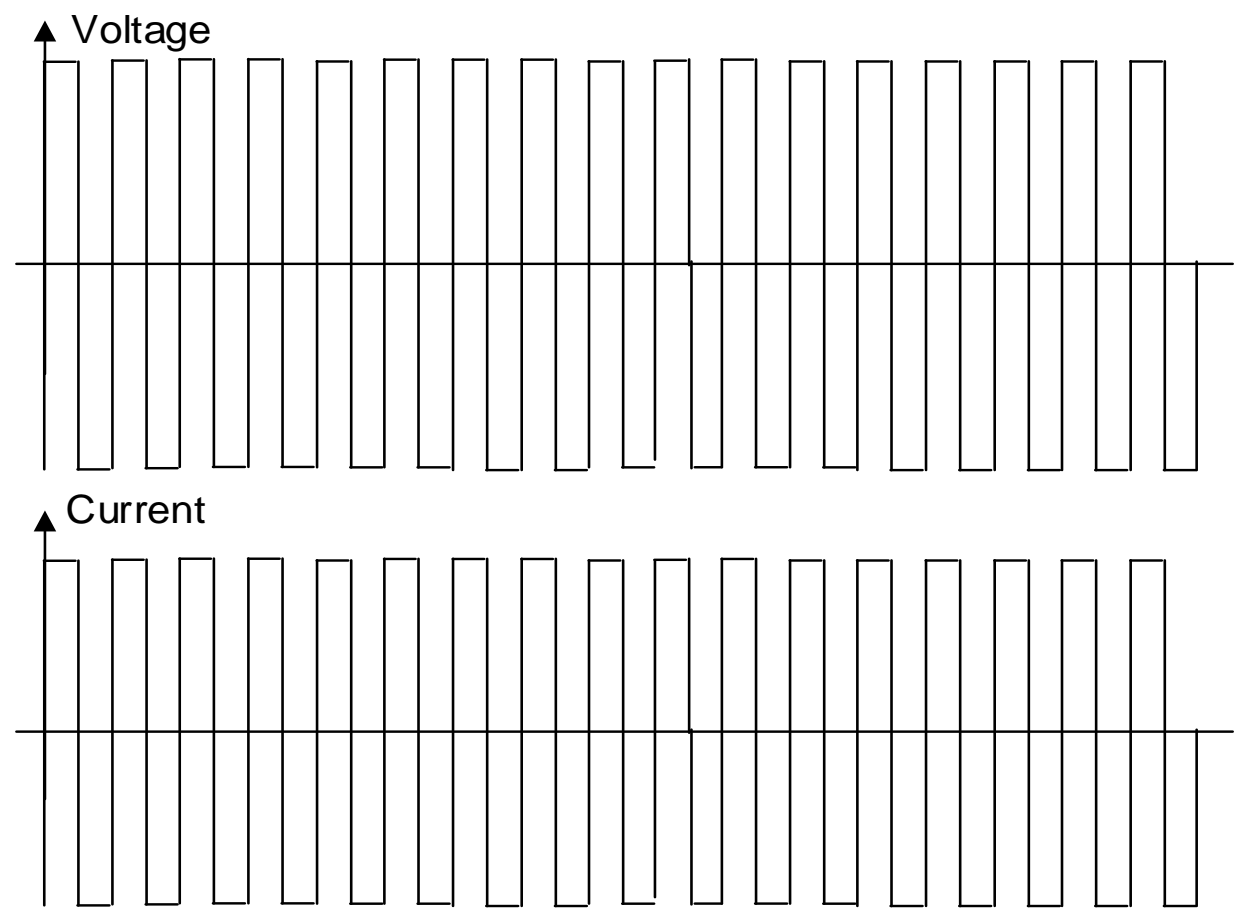

Figure 8: Current and voltage for pulse switching. 
Table 1: Comparison of the AC and hybrid distribution of PV.

\begin{tabular}{|c|c|c|c|}
\hline & AC distribution & $\begin{array}{c}\text { Hybrid } \\
\text { distribution }\end{array}$ & Comparison \\
\hline \multicolumn{4}{|c|}{ Power electronic converters } \\
\hline No of IGBTs & 6 & 4 & $\begin{array}{l}\text { AC distribution scheme } \\
\text { requires more IGBTs than the } \\
\text { proposed scheme }\end{array}$ \\
\hline $\begin{array}{l}\text { Voltage rating of } \\
\text { IGBTs }\end{array}$ & $d_{1} V_{P V}$ & $\mathrm{~d}_{2} \mathrm{~V}_{\mathrm{PV}}$ & $\begin{array}{l}\text { From equations (8) and (14), } \\
\mathrm{d}_{1} / \mathrm{d}_{2} \text { is } 3.15\end{array}$ \\
\hline $\begin{array}{l}\text { Current rating of } \\
\text { IGBTs }\end{array}$ & $0.33 \frac{\mathrm{P}_{\mathrm{PV}} \times \eta_{D C} \eta_{V S C}}{\mathrm{~V}_{\mathrm{Grid}}}$ & $\frac{\mathrm{P}_{\mathrm{PV}} \times \eta_{D C} \eta_{\text {Pulse }}}{\mathrm{V}_{\text {Grid }}}$ & $\begin{array}{l}\text { Current rating of the IGBTs } \\
\text { required for the proposed } \\
\text { scheme is } 3 \text { time that of the AC } \\
\text { scheme }\end{array}$ \\
\hline Switching pattern & PWM switching & $\begin{array}{l}\text { Square wave } \\
\text { switching }\end{array}$ & $\begin{array}{l}\text { In order to minimise the size of } \\
\text { the filter required, PWM } \\
\text { switching should perform in } \\
\text { higher frequency than square } \\
\text { wave switching }\end{array}$ \\
\hline $\begin{array}{l}\text { Conduction losses in } \\
\text { IGBTs }\end{array}$ & $3 \times \mathrm{I}_{\text {Grid }} \times \mathrm{V}_{\mathrm{ON}}$ & $2 \mathrm{I}_{\text {Grid }} \times \mathrm{V}_{\mathrm{ON}}$ & $\begin{array}{l}\text { Conduction losses are higher in } \\
\text { the AC scheme }\end{array}$ \\
\hline $\begin{array}{l}\text { Switching losses in } \\
\text { IGBTs }\end{array}$ & $3 \mathrm{~V}_{\mathrm{dc}} \mathrm{I}_{\text {Grid }} \mathrm{f}_{\mathrm{PWM}}$ & $\mathrm{V}_{\mathrm{dc}} \mathrm{I}_{\text {Grid }} \mathrm{f}_{\text {pulse }}$ & $\begin{array}{l}\text { Since } f_{P W M} \gg>f_{\text {pulse }} \text { swiching } \\
\text { losses are much higher in the } \\
\text { AC scheme }\end{array}$ \\
\hline \multicolumn{4}{|c|}{ 132/33 kV Transformer } \\
\hline VA rating & \multicolumn{3}{|c|}{$\begin{array}{l}\text { Equal to the total load } \\
\text { Both carries VA rating of all AC loads plus all DC loads }\end{array}$} \\
\hline $\mathrm{Cu}$ losses & \multicolumn{3}{|c|}{ Equal as both transformers are identical } \\
\hline Iron losses & $\begin{array}{l}\text { Only } 50 \mathrm{~Hz} \text { current flows } \\
\text { thus iron losses are less }\end{array}$ & $\begin{array}{l}\text { High frequency } \\
\text { current flows in the } \\
\text { secondary thus } \\
\text { losses are high }\end{array}$ & $\begin{array}{l}\text { Iron losses include hysteresis } \\
\text { losses proportional to } f B^{x} \text { and } \\
\text { eddy current losses proportional } \\
\text { to } f^{2} B^{2}\end{array}$ \\
\hline \multicolumn{4}{|c|}{ 33/1 kV Transformer } \\
\hline $\begin{array}{l}\text { Winding arrangement } \\
\& \text { foot print }\end{array}$ & $\begin{array}{l}\text { Three phase } 50 \mathrm{~Hz} \\
\text { transformer }\end{array}$ & $\begin{array}{l}\text { A single phase high } \\
\text { frequency } \\
\text { transformer }\end{array}$ & $\begin{array}{l}\text { The foot-print of the single } \\
\text { phase high frequency } \\
\text { transformer is much smaller } \\
\text { than the 3-phase transformer. }\end{array}$ \\
\hline $\mathrm{Cu}$ losses & $3 I_{p v, p}^{2} R_{p}$ & $I_{p v, 1 p}^{2} R_{1 p}$ & $\begin{array}{l}\text { Per phase current in AC scheme } \\
\text { will be lower than single-phase } \\
\text { transformer. Thus } \mathrm{Cu} \text { losses in } \\
\text { the hybrid distribution may be } \\
\text { higher than AC scheme. }\end{array}$ \\
\hline Iron losses & $\begin{array}{l}\text { Only } 50 \mathrm{~Hz} \text { current flows } \\
\text { thus iron losses are less. }\end{array}$ & $\begin{array}{l}\text { High frequency } \\
\text { current flows thus } \\
\text { losses are high }\end{array}$ & $\begin{array}{l}\text { AC scheme utilises a } 3 \text {-limb or } \\
\text { 5-limb core thus core area is } \\
\text { much higher than that required } \\
\text { for the high frequency } \\
\text { transformer. This increases the } \\
\text { losses. }\end{array}$ \\
\hline
\end{tabular}




\begin{tabular}{|c|c|c|c|}
\hline \multicolumn{4}{|c|}{ 33/0.4 kV Transformer } \\
\hline $\begin{array}{l}\text { Winding arrangement } \\
\& \text { foot print }\end{array}$ & $\begin{array}{l}\text { Three phase two winding } \\
\text { transformer }\end{array}$ & $\begin{array}{l}\text { Three phase three } \\
\text { winding transformer }\end{array}$ & $\begin{array}{l}\text { Even though the proposed } \\
\text { scheme has a secondary and } \\
\text { tertiary windings the addition } \\
\text { of their VA rating is equal to } \\
\text { the VA rating of the secondary } \\
\text { of the AC scheme. Therefore } \\
\text { the foot print may be } \\
\text { comparable. }\end{array}$ \\
\hline Conduction losses & $\begin{array}{l}\text { Three phase transformer } \\
\mathrm{Cu} \text { loss plus all the losses } \\
\text { in the downstream AC to } \\
\text { DC converters }\end{array}$ & $\begin{array}{l}\text { Three phase } \\
\text { transformer Cu loss } \\
\text { plus losses in the } \\
\text { rectifier that used to } \\
\text { convert pulse output } \\
\text { to DC }\end{array}$ & $\begin{array}{l}\text { As the VA ratings of both } \\
\text { schemes are equal and the } \\
\text { losses associated with AC to } \\
\text { DC converter is high, the } \\
\text { conduction losses of the AC } \\
\text { scheme may be much higher }\end{array}$ \\
\hline Iron losses & $\begin{array}{l}\text { Only } 50 \mathrm{~Hz} \text { current flows } \\
\text { thus iron losses are less. }\end{array}$ & $\begin{array}{l}\text { High frequency } \\
\text { current flows thus } \\
\text { losses are high }\end{array}$ & \\
\hline
\end{tabular}

Table 2: System parameters.

\begin{tabular}{|c|c|c|}
\hline Component & Parameter & Value \\
\hline \multirow[t]{11}{*}{ PV array } & No of modules in series & 27 \\
\hline & No of modules in parallel & 58 \\
\hline & No of cells in series per module & 60 \\
\hline & No of cell sting in parallel per module & 2 \\
\hline & Power output of each module & $250 \mathrm{~W}$ \\
\hline & Open circuit voltage of the module & $37.8 \mathrm{~V}$ \\
\hline & Short circuit current of the module & $8.89 \mathrm{~A}$ \\
\hline & Cell area & $78 \mathrm{~mm} \times 156 \mathrm{~mm}$ \\
\hline & Series resistance & $0.02 \Omega$ \\
\hline & Shunt resistance & $1000 \Omega$ \\
\hline & Diode ideality factor & 1.0694 \\
\hline High frequency transfer & Ratio & $1: 10 \mathrm{kV}$ \\
\hline
\end{tabular}




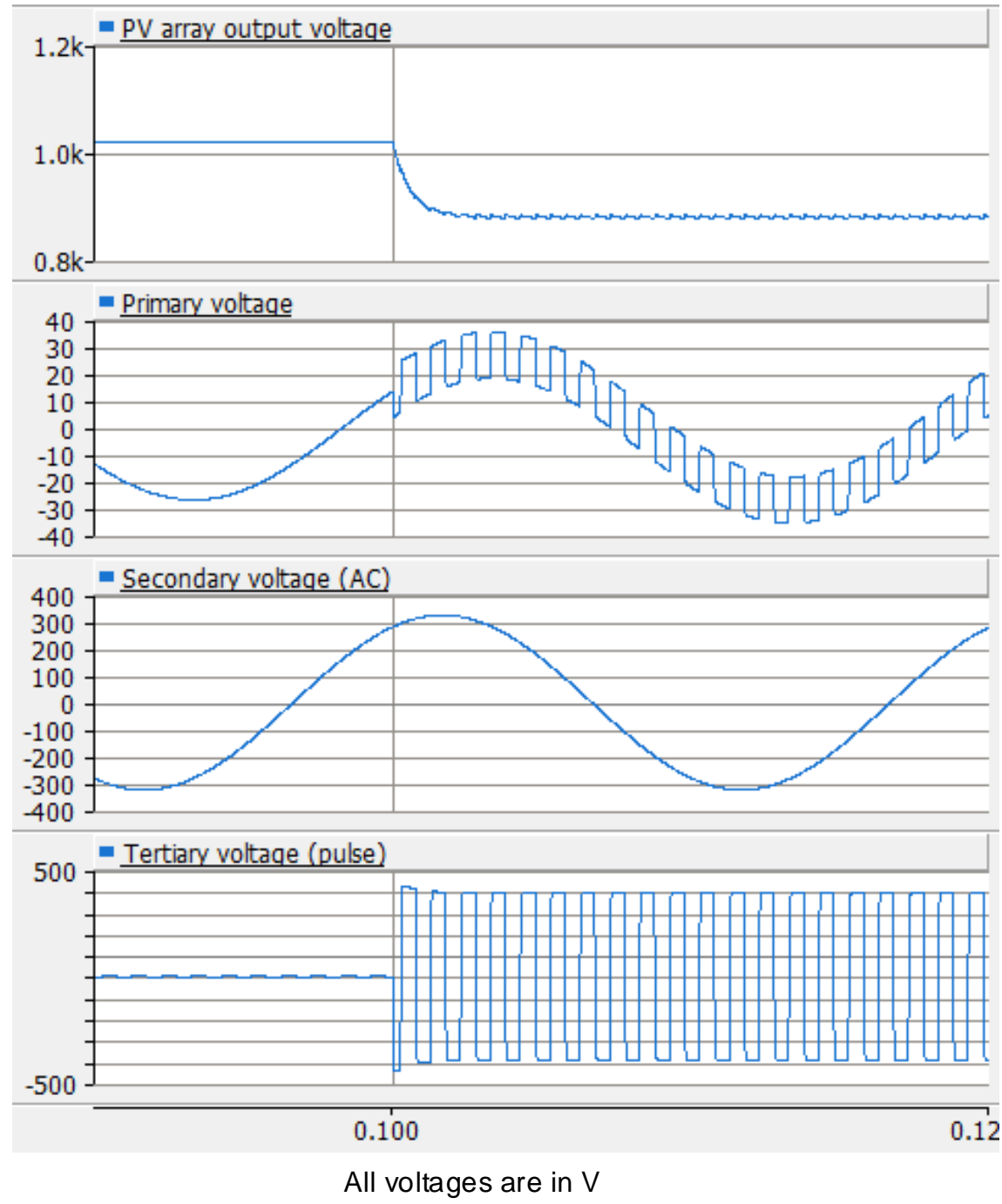

Figure 9: Voltage at different points.

\section{SIMULATION STUDY}

\section{System under study}

In order to perform the simulation study the system parameters given in Table 2 were used.

Ratios of the three winding transformer was selected such that per phase secondary AC voltage is equal to $230 \mathrm{~V}$ and DC voltage is equal to $380 \mathrm{~V}$.

From equation (4), the rms value of the $\mathrm{AC}$ voltage $V=\sqrt{3} k^{\prime} \times \frac{33 \times 10^{3}}{\sqrt{3}}=230$ and $k^{\prime}=0.007$.

From equation (5), the DC voltage $=3 k^{\prime \prime}\left|v_{\text {pulse }}(t)\right|=380 \mathrm{~V}$
Since $\left|v_{\text {pulse }}(t)\right|=27 \times 31.2$ (output voltage of the PV array) $\mathrm{x} 10$ (pulse transformer ratio) $=8.5$ $\mathrm{kV}$.

Therefore, $k^{\prime \prime}=0.015$

\section{Simulation results}

The circuit shown in Figure 2 was implemented in PSCAD/EMTDC simulation environment. It was assumed that the AC load is unity power factor. Figures 9 and 10 show the PV array output and three winding transformer currents and voltages. The PV panel was open until 0.1 sec and then connected to the circuit. 


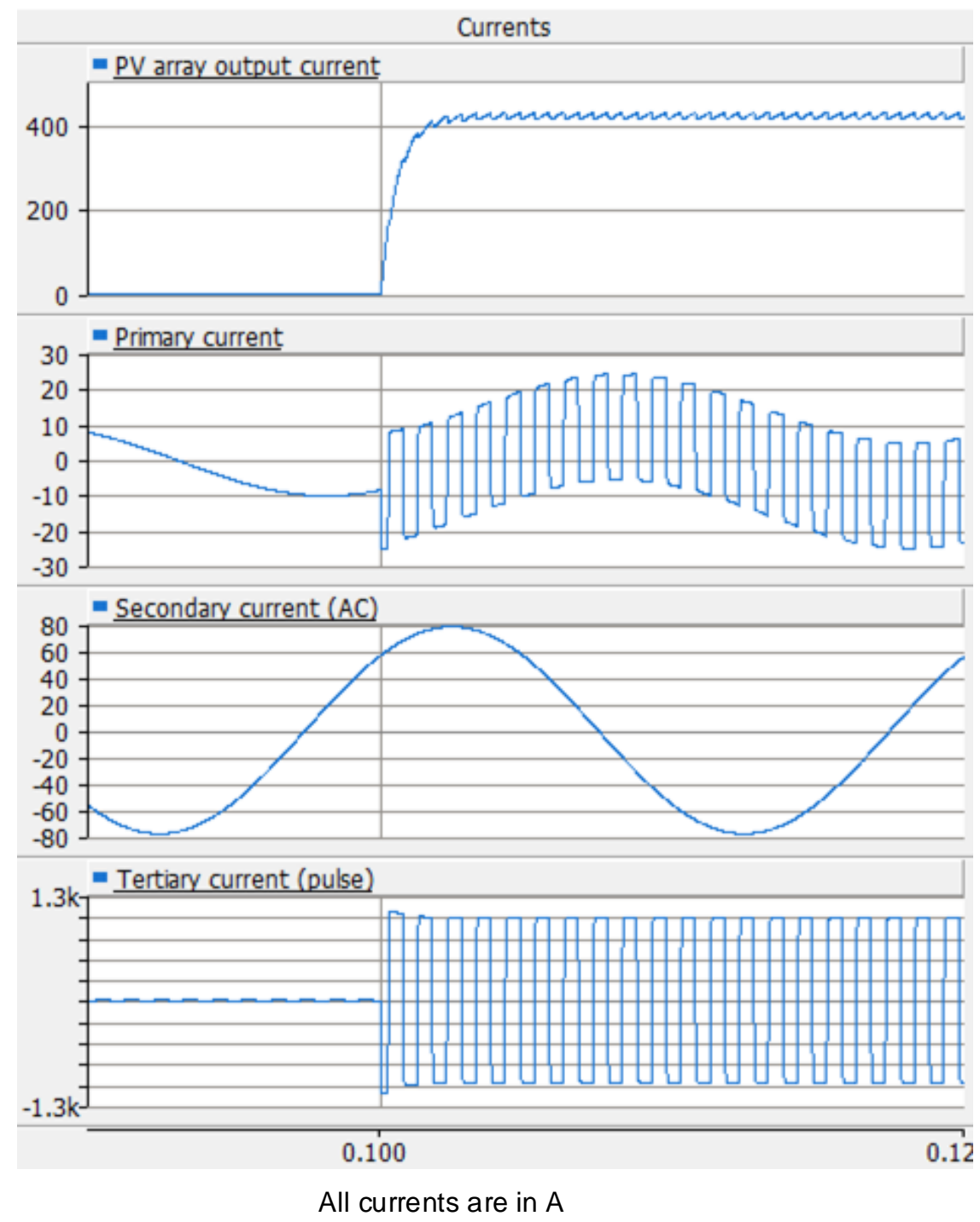

Figure 10: Currents at different points.

\section{PRACTICAL IMPLEMENTATION}

In laboratory implementation shown in Figure 11, two similar types of transformers were used as the injection transformer and the separation transformer. Transformer tapping voltages were used accordingly. They are rated at $2 \mathrm{kVA}$ with a primary voltage of $220 \mathrm{~V}$ and Secondary/Tertiary voltage of $63.5 \mathrm{~V}$.

After the injection of pulse voltage into the neutral point of the injection transformer secondary, the hybrid waveform was obtained. Pulse signal is superimposed on AC signal as shown in Figure 12.
Figure 13 shows the output of the separation transformer. As can be seen both AC and pulsed DC can be extracted from the separation transformers.

Secondary and tertiary voltages expected for given input voltages were calculated using equations (4) and (5). They are compared in Table 4. Even though the output voltage of both injection and separation transformers are comparable, the output pulse voltage shows a considerable difference. This is mainly due to the distorted pulse voltage obtained experimentally (Figure 13(b)). 


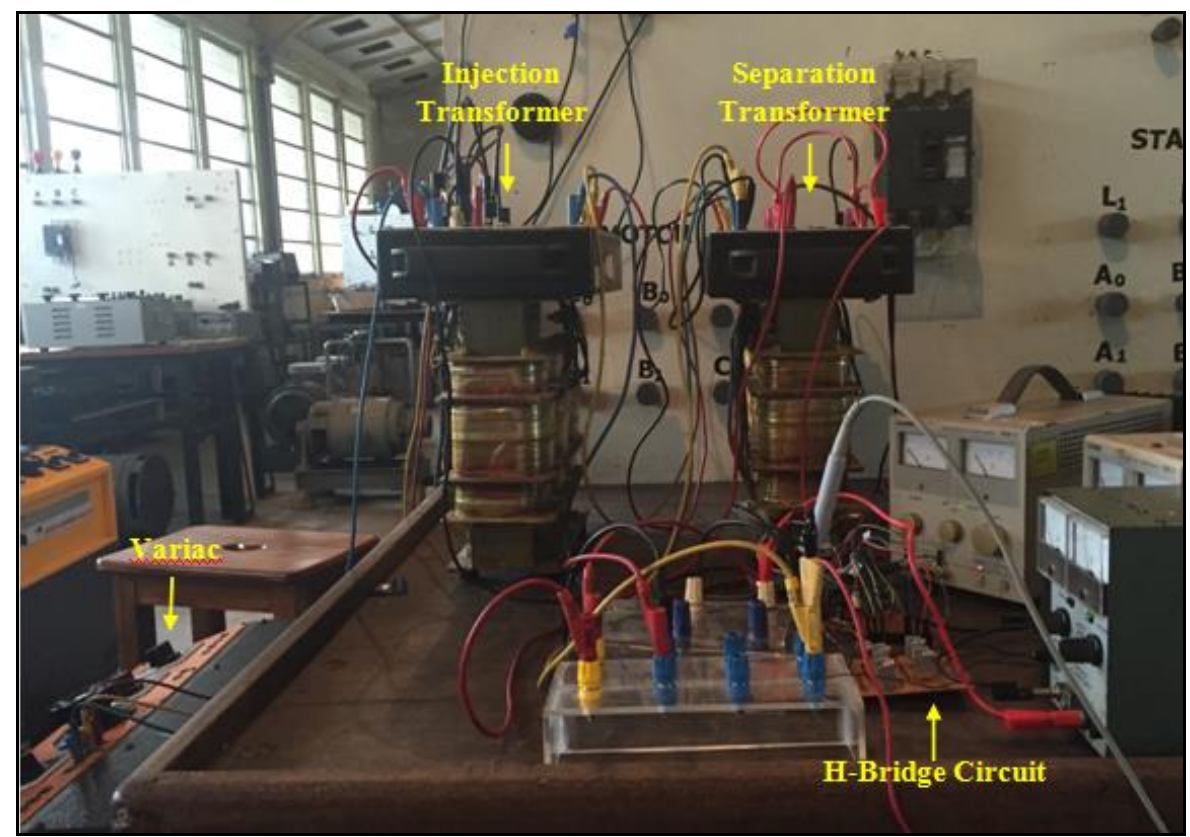

Figure 11: Laboratory setup.

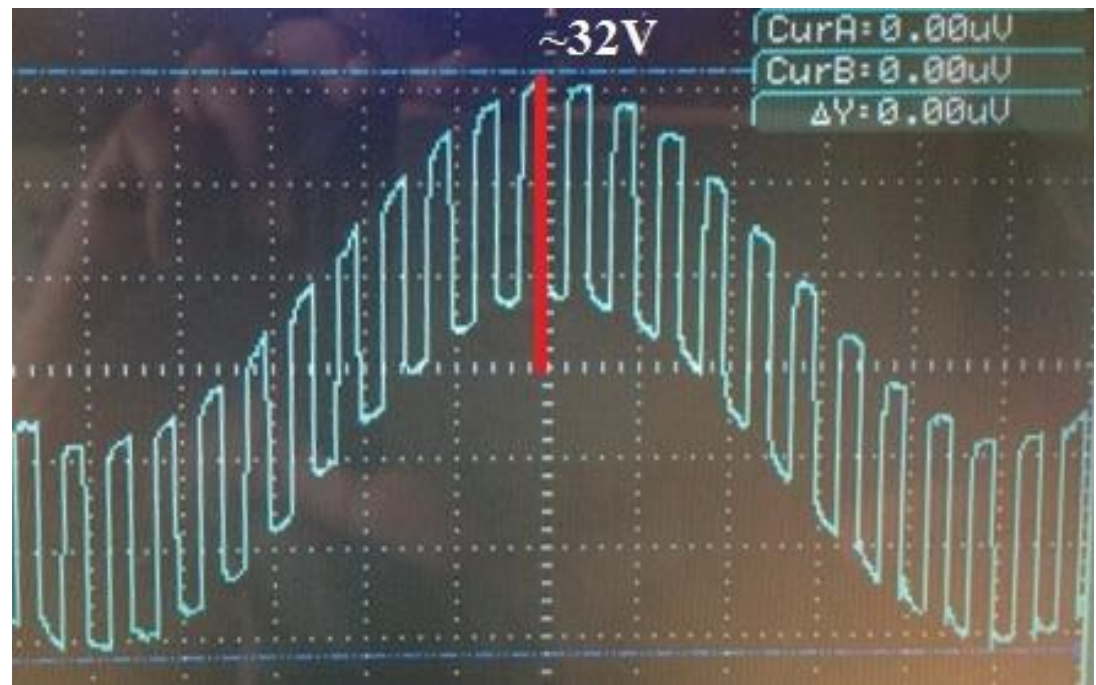

Figure 12: Output of the injection transformer when $12 \mathrm{~V}$ pulse is injected from the neutral.

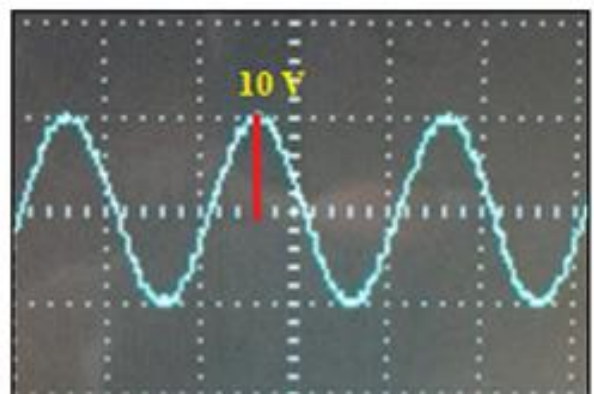

(a)

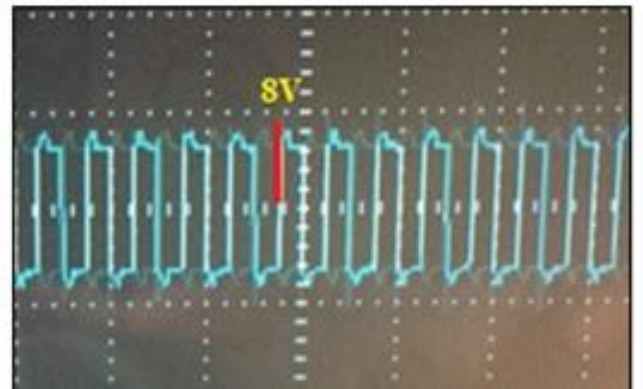

(b)

Figure 13: Outputs of separation transformer. (a) AC voltage from the secondary. (b) Pulse voltage from the tertiary. 
Table 4: Calculated and experimentally obtained output voltages.

\begin{tabular}{llcc}
\hline & Parameter & $\begin{array}{c}\text { Calculated } \\
\text { voltage }(\mathbf{V})\end{array}$ & $\begin{array}{c}\text { Experimentally obtained } \\
\text { voltage }(\mathbf{V})\end{array}$ \\
\hline $\begin{array}{l}\text { Injection } \\
\text { Transformer }\end{array}$ & Maximum of output voltage & 32.2 & 32 \\
\hline $\begin{array}{l}\text { Separation } \\
\text { Transformer }\end{array}$ & Output AC voltage (rms) & 7.15 & 7.07 \\
\cline { 2 - 4 } & Output pulse voltage (max) & 10.39 & 8 \\
\hline
\end{tabular}

\section{CONCLUSION}

With increasing demand of electricity, means of improving energy efficiency is a must. It is well recognised that energy losses in conversion stages when connecting renewables to AC system at the source end and when connecting many consumable loads at the demand side incur losses. These losses can be eliminated if loads are fed with $\mathrm{AC}$ or DC depending on the nature of the load. Further, in order to improve the efficiency of the overall system, it is important to integrate renewable energy sources such as PV and wind with minimum energy losses.

This paper presented a hybrid distribution system that can enhance the energy efficiency of medium and low voltage distribution networks. An injection transformer and a separation transformer was designed to inject renewable energy sources in an energy efficient way and to supply AC and DC loads directly. The concept was proved using simulations and practical implementation. Further, a comparison was made to show the rating of different components and losses associated with different systems in $\mathrm{AC}$ and the proposed schemes.

\section{ACKNOWLEDGEMENT}

This work was carried out as part of the NRC research grant no. NRC 14-15. Authors would like to thank NRC for financial support provided for this study.

\section{REFERENCES}

Andersen, B. R., Barker, C. D.(2000). A new era in HVDC.IEE Review 46: 33-39.

Asplund, G., Ericsson, K., Svensson, K. (1998).HVDC Light - DC Transmission based on Voltage Sourced Convertors, ABB Review 1: 4-9.

Basu, K.P. and Rahman,H. (2005). Feasibility Study of Conversion of Double Circuit ac Transmission Line for Simultaneous ac-dc Power Transmission, International Conference on
Power Electronics and Drives Systems, Kuala Lumpur, Malaysia, pp. 972 - 976.

Choudhary,V.,Kadir, A. and Gupta,P. (2011).A novel idea: simultaneous ac-dc power transmission. International Journal of Advanced Engineering Technology.II: 470-474.

Gopi, C. and Kishor,M. (2016). Power Upgrading of Transmission Line by Injecting DC Power in to AC line with the help of ZIG-ZAG Transformer.International Journal of Engineering Research and Applications 2: 10421047.

Hammerstrome, D. J. (2007). AC Versus DC Distribution Systems - Did We Get Right?.IEEE Power Engineering Society General Meeting, Tampa, USA, pp 1-5.

Kirby, N. M., Xu, L., Luckett, M., and Siepman, W. (2002).HVDC Transmission for Large Offshore Wind Farms, IEE Power Engineering Journal 16: 135-141.

Korytowski, M. (2011). Comparative analysis of medium voltage $\mathrm{DC}$ and $\mathrm{AC}$ network infrastructure models, Master's thesis, University of Pittsburgh.

Pasonen, R. (2014).AC/DC hybrid distribution system concept, Research Report, VTT-R. Available at: https://www.google.co.uk/url?sa=t\&rct=j\&q=\&es $\mathrm{rc}=\mathrm{s} \&$ source $=$ web $\& \mathrm{~cd}=1 \& \mathrm{cad}=\mathrm{rja} \&$ uact $=8 \& \mathrm{ved}$ $=0$ ahUKEwitsoiX9-

HQAhVDGsAKHV8mAmoQFggcMAA\&url=htt ps\%3A\%2F\%2Fportal.cleen.fi\%2F_layouts\%2FI WXmlPublications.aspx\%3FSource\%3DSGEM \%26FileId\%3D2452\&usg=AFQjCNFrnABypuc3 sbtyy7jV_0v7kbtRAA\&sig2=Evh03clW5n3JV8 LWylDwzA (Access on: 07/12/2016).

Salonen, P., Kaipia, T., Nuutinen, P., Peltoniemi, P., Partanen, J. (2008). An LVDC distribution system concept, Nordic Workshop on Power and Industrial Electronics, Finland.

Starke, M., Tolbert, M., Ozpineci, B. (2008). AC vs DC distribution: a loss comparison, IEEE/PES Transmission and Distribution Conference and Exposition,Latin America, pp 42.

Zhang, W., Liang, H., Bin, Z., Li, W., Guo, R. (2012). Review of DC Technology in Future Smart Distribution Grid, IEEE PES Innovative Smart Grid Technologies, Tianjin, China, pp 1-4. 